\title{
EMPREENDEDORISMO E ENSINO SUPERIOR POLTÉCNICO: CONTORNOS DE IMPLEMENTAÇÃO DO PROGRAMA POLIEMPREENDE
}

\author{
ENTREPRENEURSHIP AND POLYTECHNIC HIGHER EDUCATION: \\ OUTLINES OF THE POLIEMPREENDE PROGRAM IMPLEMENTATION \\ EMPRENDEDURISMO Y ENSEÑANZA SUPERIOR POLITÉCNICA: \\ CONTORNOS DE IMPLEMENTACIÓN DEL PROGRAMA \\ POLIEMPREENDE
}

Luis Sousa (luissousa@esev.ipv.pt)*

\section{RESUMO:}

A aparente inadequação das qualificações obtidas pelo número crescente de licenciados e as exigências do mercado de trabalho, vêm mudando a direção e a proeminência do fenómeno do desemprego, resultando numa reestruturação da desclassificação do emprego jovem. A crescente falta de linearidade entre o sistema de ensino superior e o mercado de trabalho tem vindo, assim, a aumentar em Portugal, revelando novas lacunas, tornando o processo de transição de diplomados do ensino superior para o mercado de trabalho e para a vida adulta, num processo complexo e instável. Esta situação é representada pelo aumento da concorrência no mercado de trabalho, pelas taxas de desemprego e pela crescente falta de ligação entre as qualificações, competências pessoais e profissionais, oportunidades de carreira e expetativas profissionais. Este movimento vem ganhando, nos últimos anos, vitalidade crescente e, atualmente, representa uma grande preocupação para as várias instituições que estão diretas e indiretamente envolvidas neste processo. Promover o empreendedorismo constitui hoje um dos principais aspetos na formação de graduados e, simultaneamente, um apoio à transição para o processo de trabalho. $\bigcirc$ Poliempreende (9 a edição em 2013) representa os esforços do Ensino Superior Politécnico neste movimento, e nós pretendemos aqui contextualizálo no cenário nacional, assim como verificar, de uma forma exploratória, os seus contornos de aplicação, até ao momento.

Palavras-chave: Ensino Superior; Politécnico; Empreendedorismo; Transição para o trabalho. 


\section{ABSTRACT:}

The apparent inadequacy of qualifications obtained by the growing number of graduates that stays, nevertheless, and the demands of the labour market, has been changing the direction and prominence of the unemployment phenomenon, resulting also in the restructuring concept of disqualified employment affecting the younger population. The growing lack of linearity between the higher education system and the labour market has been increasing in Portugal, revealing new gaps, making the transition process from higher education graduates to work and to the adulthood, into a complex and unstable process. This situation is actually represented in the increased competition in the labor market, unemployment rates and the growing mismatch between qualifications, skill's, career opportunities and personal and professional expectations. This movement has been gaining, in recent years, an increasing vitality and, nowadays, it is a great concern for the various institutions that are directly and indirectly involved in this process. Promote the entrepreneurship represent one of the main aspects in the graduates training and simultaneously a support the transition to work process. Poliempreende (9th Edition in 2013) represented the Polytechnic's higher education efforts in this movement, and we pretend here, contextualize it on the national scene, ad check, in an exploratory ways, its applications outlines.

KeyWords: Polytechnic's, Entrepreneurship, Transition to Work, Higher education.

\section{RESUMEN:}

La aparente insuficiencia de las competencias adquiridas por el creciente número de graduados y las demandas del mercado de trabajo ha cambiando la dirección y el protagonismo del fenómeno del desempleo, lo que resulta en una reestructuración e descalificación del empleo juvenil. La creciente falta de linealidad entre el sistema de educación superior y el mercado laboral se ha incrementando en Portugal, revelando nuevas brechas, haciendo la transición para el mercado laboral y lo acceso à la vida adulta en un proceso complejo e inestable. Esta situación está representada por una mayor concurrencia en el mercado laboral, pelo aumento de la tasa de desempleo y por la creciente falta de conexión entre las habilidades, competencias personales y profesionales, las oportunidades de carrera y las expectativas profesionales. Este movimiento ha ganado en los últimos años, el aumento de la vitalidad y en la actualidad representa una gran preocupación para las diversas instituciones que están directa o indirectamente involucrados en este proceso. Promover el espíritu empresarial es hoy uno de los temas clave en la formación de postgrado y apoyar la transición al proceso de trabajo al mismo tiempo. El Poliempreende (9 a edición en 2013) representa el esfuerzo de la Politécnica en este movimiento, y tenemos la intención aquí, para contextualizarlo en el escenario nacional, de forma exploratoria, su aplicación esbozo hasta la fecha.

Palavras clave: Educación Superior; Politécnico; Emprendimiento; Transición al trabajo. 
*Luís Nuno Figueiredo e Sousa. Sociólogo PhD - Professor-Adjunto

ESEV/PV, onde exerce docência desde 2000 na área disciplinar de

Ciências Sociais/Departamento de Arte e Comunicação; Investigador Integrado do Centro de Estudos em Educação, Tecnologias e Saúde do

IPV desde 2011; Investigador Associado do Instituto de Sociologia da Universidade do Porto, desde 2008.

Submitted: $11^{\text {th }}$ Febuary 2014

Accepted: $26^{\text {th }}$ March 2014 


\section{1 - EMPREENDEDORISMO E ENSINO SUPERIOR POLITÉCNICO}

Desde os anos 90 do séc. $X X$, que se verifica uma reestruturação profunda dos modelos de transição para o mercado de trabalho (Rose, 1998), distribuindo os jovens diplomados por diferentes itinerários profissionais, onde predominam dimensões de incerteza, flexibilidade e reversibilidade (Galland, 1991), integrando-se num movimento mais vasto de "crise de identidades" (Dubar, 2001).

Perante estes impasses, as "gerações de fronteira"/ "gerações sanduíche"/ "jovens adultos" (Pais, 2005) vêem-se confrontados com modelos atuais de transição, que implicam processos de "individualização" ou "modernização flexível" (Beck, Giddens e Lasch, 1994), em (des)articulação com processos de institucionalização, que caraterizam as estruturas de oportunidades propostas por políticas públicas ou mesmo por lógicas de mercado. As recentes orientações das políticas públicas de ensino, no âmbito europeu, apresentam recomendações concernentes à "educação empreendedora" ${ }^{21}$, através de iniciativas dedicadas ao desenvolvimento de atributos e competências empreendedoras. Tais competências são consideradas essenciais, tanto para a aprendizagem ao longo da vida, como para a empregabilidade, como forma de fomentar a satisfação pessoal e profissional, a inclusão social e a cidadania ativa. $\bigcirc$ que se encontra aqui em questão não é somente o facto de os jovens evidenciarem cada vez maior dificuldade em aceder ao emprego; eles denotam, simultaneamente, uma crescente dificuldade em encontrar empregos enquadrados, na área da formação académica obtida, o que levanta a questão do equilíbrio entre oferta formativa, oportunidades e exigências ao nível laboral.

A criação do próprio negócio ou empresa afigura-se, cada vez mais, como uma forma de criação do próprio emprego, para muitos jovens diplomados. São diversos os fatores e agentes que interagem neste processo. Desde logo, o Estado, através das políticas ativas de emprego, da promoção do empreendedorismo ou das políticas de fomento à criação e desenvolvimento de PME's, mas igualmente outros atores (sistema de ensino, a familia ou as redes sociais). A inovação deve ser vista como um processo socialmente construído (também pelos seus atores), assim como com as relações entre eles, pelo que adquire relevo a "teoria do ator-rede" (Oliveira, 2008).

21 http://eur-lex.europa.eu/LexUriServ/LexUriServ.do?uri=OJ:L:2006:394:0010:0018:pt:PDF http://eur-lex.europa.eu/LexUriServ/LeUriServ.do?uri=OJ:C:2011:070:0001:0003:PT:PDF http://eur-lex.europa.eu/LexUriServ/LexUriServ.do?uri=COM:2009:0640:FIN:PT:PDF 
Para Giret (2000), o diploma representa simplesmente uma característica individual, perante fatores mais discriminatórios, como são as características pessoais (o género, a origem social), as políticas de gestão de pessoal (a duração dos primeiros empregos, a utilização de diferentes tipos de contratos, os períodos experimentais, as medidas de apoio aos mais jovens), as estratégias de procura de emprego e a utilização de certos canais de informação sobre o mercado de trabalho e o espaço (o território é central, até porque a mobilidade geográfica é um fator cada vez mais ligado a este processo). Martínez, Mora e Vila (2007) salientam, ainda, os aspetos sociodemográficos (país/região), a experiência educacional, o número de anos de educação superior, a educação/formação contínua, os modos de aprendizagem e de ensino, as competências e timing da graduação, defendendo que estes elementos influenciam a decisão ocupacional, depois da obtenção do diploma de ensino superior.

Consequentemente, a questão do património individual detém particular pertinência, neste processo. Por conseguinte, segundo Lahire (2005), a captação das realidades mais individuais não remete, nem para uma singularidade inquestionável dos contornos individuais, nem para a "liberdade de escolha" de indivíduos "autónomos" (e imunes a todos os determinantes sociais), remete, sim, para a estrutura de conjunto das sociedades que as construíram, para a pluralidade de grupos (ou de instituições) e para a multiplicidade dos quadros de vida social que cada indivíduo é suscetível de frequentar, simultânea ou sucessivamente, estando ligadas à forte diferenciação social das funções características das sociedades. A questão da origem social influencia as aspirações escolares dos jovens, como assinala Boudon (1977), e reflete, simultaneamente, a imagem social que a famlia possui de si própria. Bourdieu (1980b) avança, neste contexto, com o conceito de capital social, conceptualizando a teoria da dominação, que surge como um mecanismo social alicerçado nos recursos sociais do ator, nas relações de conhecimento e reconhecimento. Na atualidade, a necessidade de conhecimento representa um fator de extrema importância, no que respeita ao movimento de integração social que, invariavelmente, se encontra ligado ao exercício do trabalho (OCDE, 2007). Assiste-se, assim, a uma transposição de modelo de ensino superior "( ) from elite to a mass system has had a fundamental impact on the labour supply and occupational structure, challenging employers' and graduates' perceptions of the relationship between Higher Education and employment." (Purcell et al, 2007: 57/58).

Em Portugal, este papel tem sido feito fundamentalmente com a implementação e desenvolvimento do ensino superior politécnico. Não podemos esquecer que, na linha da perspectiva de Rose (1998), o 
grande tutor do mercado de trabalho dos jovens e o responsável pela política estrutural de transição profissional é, inquestionavelmente, o Estado, isto porque"( ) les politiques d'emploi sont des contructions sociales qui demandent la participation, l'engagement et la coopération d'acteurs sociaux et des personnes. L'État est l'un des acteurs, l'union européenne aussi. Mais la dimension locale des actions est essentielle." (Barbier, 1997: 66).

Nos países do Sul da Europa, as intervenções de financiamento europeu destinadas a inverter sistemas apresentam-se pouco capazes e sem tradição na ação pública. Assim, "( ) para compreender a produção do bem-estar na Europa do Sul importa olhar para a forma como proteção social, mercado de trabalho e agregados familiares interagem, bem como para a forma como neste processo instituições à partida semelhantes se encastram em realidades sociais distintas." (Mozzicafreddo, 1992: 38).

É neste âmbito que se enquadra o programa Poliempreende, tendo como objetivo máximo incutir e estimular o empreendedorismo, bem como proporcionar possíveis saídas profissionais, de preferência através da criação do próprio emprego. É um projeto concebido para promover a mudança de atitudes dos atores académicos participantes, induzindo-os a incorporar, nas suas atividades regulares, o desenvolvimento e a aplicação de métodos para a valorização do conhecimento gerado, no sentido da assimilação do empreender, contribuindo, paralelamente, para o enriquecimento curricular dos seus participantes. Está orientado para dar à sociedade e à economia um forte e sério contributo, através da constituição de empresas de cariz inovador e de implantação regional, que possam ser levados à prática e, ainda, para o fomento do empreendedorismo, nas regiões de influência das instituições de ensino politécnico.

Pretende-se, neste contexto, contribuir para uma discussão crítica dos movimentos de empreendedorismo e criação de empresas, no ensino superior politécnico em Portugal, assentes na promoção de novas formas de contacto entre politécnicos, (ex)alunos e mercado de trabalho e nos novos desafios institucionais de promoção do desenvolvimento económico e social, a nível regional/nacional. Neste âmbito, o programa Poliempreende apresenta-se como um instrumento de dinamização institucional do empreendedorismo e emprego e de desenvolvimento regional e nacional. $\bigcirc$ concurso $^{22}$ destina-se a

\footnotetext{
22 Os prémios do Concurso Poliempreende compreendem duas tipologias: Prémios, pecuniários, Nacionais e Regionais. Prémios Complementares Nacionais ou Regionais.

Prémios Nacionais: $1^{\circ}-10000 € ; 2^{\circ}-5000 € ; 3^{\circ}-3000 €$

Prémios Regionais: $1^{\circ}-2000 € ; 2^{\circ}-1500 € ; 3^{\circ}-1000 €$

Prémios Complementares: Prémio de Empreendedorismo, que pretende premiar a equipa que se revelar ao júri como a mais empreendedora, patrocinado pelo Patrono do Concurso, o Comendador
} 
estudantes e diplomados de Escolas Superiores dos Institutos Politécnicos de qualquer grau, a docentes dos politécnicos ou outros indivíduos (os quais, por este facto, ficam impedidos de pertencer ao júri responsável pela apreciação das propostas), desde que integrando equipas constituídas por alunos e/ou diplomados.

\section{2 - EMPREENDEDORISMO NO ENSINO SUPERIOR E TRANSIÇÃO PARA O TRABALHO}

Nas últimas décadas, no quadro global da reflexão sobre as relações entre a educação e o mundo do trabalho, as investigações científicas, no campo da sociologia e da economia, relativas à problemática do desemprego dos diplomados do ensino superior, complexificam-se em termos de quadros teóricos e empíricos de referência. Esta evolução conceptual comprova, por um lado, uma dificuldade crescente de acesso ao mercado laboral, por parte dos diplomados do ensino superior, uma multiplicidade evidente nas formas de acesso à vida ativa, por parte do fluxo crescente de jovens diplomados, e, paralelamente, uma dificuldade progressiva na relação entre sistema de ensino e mercado de trabalho, que tem exigido uma crescente intervenção estatal face ao desemprego. As linhas de orientação da organização da transição para o trabalho segundo Rose (1998) circunscrevem a sua efetiva organização (estado/empresas/indivíduos), estruturam todo tipo de mercados, implicam uma diversidade de situações de trabalho, dependem da transformação das condições de aquisição de saberes e saberes-fazer e contribuem para a regulação sociopolítica das populações desempregadas ou inativas. Apresenta-se, assim, progressivamente, como um processo cada vez mais longo e complexo, acarretando a assunção de estatutos instáveis, com percursos e modos de transição diferenciados, fortemente estruturados pelas empresas e poderes públicos, além do inevitável contexto formativo e familiar. Face a isto, encontra-se fortemente ligada aos movimentos económicos e à representatividade e incidência do desemprego, bem como às questões relativas ao mercado de trabalho local e nacional. Desta forma, diversos atores e intervenientes diretos entrecruzam-se neste movimento, delimitam informação, oportunidades, acesso, trajetos e hipotéticas carreiras profissionais, ultrapassando as questões

Rui Nabeiro, através do Grupo Delta, no valor de 2500€; Prémio de plano de Negócio, patrocinado pelo IAPMEI, que pretende valorizar a equipa concorrente que tenha construído o melhor plano de criação de negócio (valor a definir). 
económicas e revelando-se, cada vez mais, como um fator de estratificação social e de integração ou exclusão social. Existem, assim, diversas vantagens em articular as questões de volume, repartição e formas de emprego, até porque a organização da transição profissional gera fluxos de mão-de-obra, contribui para a categorização das populações e participa na emergência de formas precárias de emprego.

Na primeira década do século XXl, acentua-se o interesse no relacionamento entre o ensino superior e o mundo do trabalho, sobretudo ao nível das condições que os alunos possuem, no ensino superior, e de que modo as suas opções, durante este período, afetam as suas trajetórias profissionais. Apesar da obtenção do um diploma de ensino superior proteger, ainda hoje, os jovens do desemprego, o período do emprego imediato terminou há muito, para os diplomados do ensino superior e a realidade laboral apresenta desafios de crescente complexidade, pelo que o simples acesso ao estatuto de diplomado já não resolve, per si, o problema do acesso à vida ativa e, consequentemente, à vida adulta. Gangl (2002) refere mesmo que a ação individual (antes, durante e após a formação académica) se revela fundamental, quando o que está em causa é uma efetiva transição para o trabalho, no âmbito da obtenção do primeiro emprego regular.

As questões ligadas ao percurso educacional dos indivíduos, à já referida experiência profissional e redes sociais às quais os mesmos têm acesso, apresentam-se como fundamentais para o sucesso deste processo. Os recursos aos quais os jovens têm acesso, bem como as suas trajetórias e posturas individuais têm que ser tidas, inquestionavelmente, em conta, sob pena da transição se reter em questões puramente institucionais e formais, que nada se aproximam do enquadramento social atual. Isto implica, para Rose (1998), que o jovem tenha que ser considerado, não somente como sujeito, mas, paralelamente, como ator. Para Lefresne (2003) esta posição dicotómica reflete dois polos: um individualista, ao considerar os jovens agentes operativos arbitrários dos custos/benefícios das decisões, e um outro holístico, pelo facto da posição dos mesmos ser subdeterminada às estruturas económicas e sociais, nas quais se inscrevem, existindo o risco de fazer desaparecer o ator. Para Teichler (2005), o processo de transição para o trabalho complexifica-se progressivamente, o sentimento de inquietude generaliza-se e agonizase, verificando-se, em muitos países, um desfasamento, cada vez maior, entre a formação académica e a necessidade e especificidade de perfis laborais, por parte do mercado de trabalho. Consequentemente, multiplica-se o número de diplomados do ensino superior que afirmam exercer postos de trabalho desadequados, no 
que respeita ao estatuto socioeconómico usufruído e à possibilidade de aplicação dos seus conhecimentos às funções e tarefas efetivamente desempenhadas (os conceitos de sobre formação e subemprego utilizam-se, com frequência, para caracterizar este processo), num contexto de crescente instabilidade no emprego.

Atualmente, o empreendedorismo assume-se, assim, como uma das formas de acesso ao mercado de trabalho, como podemos verificar pelas diretivas comunitárias e pelas políticas nacionais (QREN 2007-2013). Em termos práticos, esta questão coloca novos e importantes desafios às instituições de ensino superior, relacionados com a sua capacidade de, juntamente com outros atores (económicos, sociais, políticos, entre outros), desenvolver o espírito e uma cultura empreendedora e de inovação. Entende-se, a esse respeito, que o contexto académico constitua uma parte importante do ambiente dos estudantes e, como tal, está numa posição central para mudar e incentivar o empreendedorismo. Ao promover, nos seus currículos e atividades, os estágios curriculares, a mobilidade estudantil (nacional e internacional), as atividades extracurriculares, o desenvolvimento de competências transversais, a formação contínua e o empreendedorismo (nas vertentes educativa e organizativa), as instituições de ensino superior representam, hoje, um fator de extrema importância, no processo de transição para o trabalho por parte dos seus diplomados. É neste âmbito que podemos enquadrar o programa Poliempreende.

McDaniel (2006) refere-se mesmo ao autoemprego, afirmando que este se apresenta como um reflexo dos recursos (educação, estatuto ocupacional, experiência laboral e apoio familiar), variando, porém, consoante a vida laboral e experiências sociais. A questão que pode ser colocada é se, efetivamente, o capital social é fator de desigualdade social, face à complexidade do processo de transição, bem como os diferentes atores implicados neste processo. O facto é que a pesquisa e o acesso ao emprego revelam lógicas diferenciadas, consoante os casos, até porque a mobilidade profissional não é, necessariamente, precedida por um período de procura de emprego. Quanto maior for o número de contactos bem colocados o indivíduo for capaz de instituir, durante a sua experiência profissional, mais oportunidades reais de encontrar bons empregos terá; paralelamente, existe, atualmente, uma progressiva formatação das procuras e ofertas de emprego e uma informatização, impulsionada pelo movimento de globalização, colocando novos parâmetros ao processo e instituindo novos contornos espácio-temporais, cada vez mais imediatistas. 


\section{3 - QUESTÕES METODOLÓGICAS}

Esta análise tem como base um inquérito por questionário ${ }^{23}$ (Sousa, 2003, 2011), disponibilizado on-line, entre o dia 15 de Julho e o dia 15 de Setembro de 2013, que pretendia abarcar a totalidade dos participantes das nove edições do programa Poliempreende. Na abordagem, exploratória foi possível verificar que a única fonte que nos permitiria uma abordagem semelhante seria a utilização da plataforma gerida pelo Instituto Politécnico de Viseu ${ }^{24}$. Esta plataforma, criada em 2012, durante a coordenação nacional IPV, não englobava, consequentemente, a totalidade dos projetos concorrentes das nove edições deste programa ${ }^{25}$, sendo que, e de uma forma previsível, as últimas edições eram as mais representativas ${ }^{26}$. Para Ghiglione e Matalon (1993), esta técnica tem como objetivo estimar grandezas "absolutas", estimar grandezas "relativas", descrever uma população ou subpopulação, na medida em que se pretende recolher informações de natureza mais factual (embora sejam sempre representações sobre o passado) e opiniões sobre o trajeto no mercado de trabalho (emprego e desemprego) do próprio inquirido, após a conclusão da licenciatura.

\begin{tabular}{cccc}
\multicolumn{4}{c}{ Quadro 1 - Participantes no programa Poliempreende } \\
\hline Projetos inseridos na plataforma IPV & $\mathrm{N}$ & $\%$ total & $\begin{array}{c}\% \text { das } \\
\text { respostas }\end{array}$ \\
\cline { 1 - 2 } Participantes Inquiridos & 148 & & \\
\hline Diplomados Inquiridos & 98 & $62 \%$ & \\
\hline
\end{tabular}

Dos 148 projetos $^{27}$ inseridos nesta plataforma, foram obtidas 98 respostas válidas, o que constitui uma taxa de resposta de 62\%. Contudo, consideramos que este programa constitui um canal privilegiado de contacto entre Politécnicos, (ex)alunos e mercado de trabalho, o que representa, na atualidade, sobretudo num ensino de índole profissionalizante, um dos maiores desafios institucionais do

\footnotetext{
${ }^{23}$ http://udi-ipg. limequery.com/index.php/survey/index/sid/615291/newtest/Y/lang/pt

Os dados resultantes da aplicação do mesmo foram tratados em SPSS versão 20.0.

${ }^{24} \mathrm{http://mww.Poliempreende.pt/}$

25 Consequentemente, as conclusões desta pesquisa, tendo presente a dimensão da amostra, não podem ser extrapoladas para a totalidade do projeto.

${ }^{26}$ Esta questão possui particular importância, já que, do ponto de vista prático, originou uma elevada percentagem de inquiridos que ainda não tinham terminado a sua formação académica, o que, do ponto de vista empírico, constitui uma limitação para esta análise, denotando, paralelamente, a impossibilidade deste mesmo programa constituir uma forma de apoio direto aos diplomados, no processo de transição ao trabalho.

${ }_{27}$ Alguns dos projetos inseridos não possuíam informação completa, nomeadamente os contatos completos, pelo que foi decidido excluí-los de imediato desta análise, por impossibilidade de estabelecer contacto com os (ex) alunos.
} 
ensino superior politécnico, na promoção do desenvolvimento económico e social a nível nacional e regional.

Neste contexto, esta análise pretende enquadrar socio geograficamente os participantes no Poliempreende, tendo presente o contexto do ensino superior em Portugal, e, de forma mais específica, evidenciar os contornos de aplicação dos projetos, por parte dos que já obtiveram o seu diploma, de forma a verificar até que ponto a sua situação profissional se poderia relacionar com este processo. Tendo presente a informação disponível de que, até ao momento, não se tinha verificado qualquer projeto aplicado, seria importante enquadrar, nesta análise, a situação profissional atual dos diplomados. Assim, dos 98 inquiridos, 54 já tinham obtido o seu diploma, o que corresponde a $36 \%$ do total do projetos inseridos na respetiva plataforma, correspondendo a 55,1\% das respostas recebidas.

Consequentemente, apresentamos, aqui, um primeiro momento de análise, centrado na análise do papel do programa Poliempreeende como dinamizador institucional do empreendedorismo dos diplomados do ensino superior politécnico e na sua função de promoção de desenvolvimento regional e nacional, tendo presente o contexto socioeconómico dos participantes. Num segundo momento, caracterizamos os contornos de aplicação dos projetos, por parte dos diplomados, bem como a sua perspetiva sobre o empreendedorismo e sobre o papel da participação neste programa, no seu percurso profissional, até ao momento.

\section{4 - CONTEXTOS SOCIOGEOGRÁFICOS E FORMATIVOS}

O ensino superior em Portugal apresenta-se, até à década de 70 do século XX, como um sistema de elites, caracterizado por baixos níveis de participação, apesar de algumas tentativas de alargar a sua abrangência, destacando-se a incorporação de uma população cuja representatividade, neste nível de ensino, é, até aí, pouco expressiva, a população feminina (Amaral e Teixeira, 2000).

Para Simão e Costa (2000), a criação do ensino politécnico surge como forma de procurar responder às expectativas do mercado de trabalho, em termos de recursos humanos, numa perspetiva desenvolvimentista, reforçar as condições de igualdade no acesso ao ensino superior, adequar os conteúdos e práticas aos diferentes grupos populacionais e estimular a formação contínua e educação recorrente. Assim, podemos afirmar que o grande objetivo político da criação deste ensino foi o de contribuir para uma melhor distribuição da oferta do 
ensino superior, cujas instituições se assumissem como "(...) centros promotores de racionalidade e de apoio ao desenvolvimento, quer no âmbito nacional, quer sobretudo no âmbito das regiões e das localidades em que cada uma destas instituições se encontra instalada." (CNE, 1990: 642).

Verifica-se, a nível europeu, nas últimas décadas, um aumento significativo da frequência do ensino superior, como comprovam os mais recentes indicadores da OCDE (2007; 2009), consequência direta "( ) d'une évolution concomitante des politiques éducatives et des comportements des jeunes et des familles, a eu des conséquences majeures pour l'université. II convient donc d'en préciser l'ampleur et les formes." (Rose, 2003: 11).

Este movimento tem, contudo, ocorrido a diferentes velocidades, exteriorizando níveis evolutivos diferenciados entre os países ocidentais, potenciado, segundo Davies, Gottsche e Bansel (2006), pela emergência de um sistema de ensino superior neoliberal, que transformou o estado administrativo, responsável pelo bem-estar do ser humano, numa economia onde o poder está concentrado nas corporações globais e assente em conhecimentos que podem ser reconfigurados segundo necessidades económicas.

Assiste-se, assim, a uma transposição do modelo de ensino superior "( ) from elite to a mass system has had a fundamental impact on the labour supply and occupational structure, challenging employers' and graduates' perceptions of the relationship between Higher Education and employment." (Purcell et al, 2007: 57/58).

A evolução ocorrida no ensino superior reflete um período de aumento exponencial da taxa de frequência deste nível de ensino, que não foi causado pelo crescimento das taxas de natalidade, mas, sobretudo, pela atratividade de novos públicos, de diferentes faixas etárias, que (re)ingressam no sistema de ensino superior. Simultaneamente, transparece um movimento de globalização da frequência deste nível de ensino e o surgimento de diferentes usos dos diplomas, instituindo novos desafios pedagógicos e funcionais e comprovando a efetiva inflação escolar e desvalorização dos diplomas.

Verifica-se, assim, uma "(...) diversificatión importante de la enseñanza superior permitindo satisfacer mejor la creciente diversidad de talentos y de motivaciones de los estudiantes, en el processo de expansión educativa, así como la gama cada vez más amplia de perspectivas profesionales que existem para los titulados superiores." (Teichler, 2005: 49). 
Quadro 2 - Caracterização sociogeográfica dos participantes do programa Poliempreende (\%)

\begin{tabular}{|c|c|c|}
\hline \multirow[b]{2}{*}{ Género } & Masculino & 33,7 \\
\hline & Feminino & 66,3 \\
\hline \multirow{5}{*}{ Idade } & Menos de 20 anos & 5,1 \\
\hline & $20-25$ anos & 55,1 \\
\hline & $26-30$ anos & 15,3 \\
\hline & $31-40$ anos & 15,3 \\
\hline & $41-50$ anos & 7,2 \\
\hline \multirow{2}{*}{ Estado civil } & Solteiro & 80,6 \\
\hline & Casado & 16,4 \\
\hline \multirow{5}{*}{ Residência ${ }^{28}$} & Leiria & 37,8 \\
\hline & Lisboa & 14,3 \\
\hline & Coimbra & 14,3 \\
\hline & Braga & 5,1 \\
\hline & Aveiro & 5,1 \\
\hline \multirow{4}{*}{ Vive } & Com os Pais & 58,1 \\
\hline & Com o conjugue & 18,4 \\
\hline & Sozinho & 13,3 \\
\hline & Com Colegas/Amigos & 8,2 \\
\hline $\mathrm{N}$ & & 98 \\
\hline
\end{tabular}

Os dados do quadro 2 corroboram o movimento verificado nas últimas décadas, em Portugal, a feminização do ensino superior (Amaral; Teixeira, 2000). Assim, verifica-se que existe uma maior representatividade feminina, com 66,7\%, sendo que destes, 55,1\% situam-se na faixa etária dos 20-25 anos. Consequentemente, e face a estes dados, cerca de $80 \%$ dos inquiridos afirmam serem solteiros, salientando-se que 58,1\% ainda vivem com os seus pais. Com trajetórias académicas cada vez mais longas, os jovens obtêm autonomia residencial cada vez mais tardiamente, aumentando a idade média de acesso ao emprego, diminuindo as entradas precoces no mercado de trabalho e arrastando temporalmente o acesso a um emprego estável, adiando a sua entrada na vida adulta. Esta situação origina uma" ( ) multiplication, au cours de la période récente, de situations intermédiaires entre l'installation des jeunes dans un autre logement que celui des parents (la décohabitation), et leur accession à une réelle indépendance résidentielle (les parents n'assurant plus le

${ }^{28}$ Com baixa representatividade, temos diversas cidades, em que se salientam Caldas da Rainha, Évora, Beja, Guarda, Castelo Branco (1\%), Viseu, Porto, Viana do Castelo, Setúbal, Estrangeiro (2\%) e Santarém com (3.1\%). Saliente-se a preponderância dos Politécnicos do litoral do país nesta amostra. 
financement de ce logement), complique l'analyse de leur accès à l'autonomie résidentielle ( )". (Villeneuve-Gokalp, 2000: 62).

lannelli e Soro-Bonmati (2006) referem-se ao modelo mediterrânico da juventude, onde os jovens apresentam trajetórias escolares longas, revelam dificuldades ao nível do primeiro emprego, vivem com os pais (mesmo após o acesso à vida ativa), de onde só saem, genericamente, quando casam (redes paternais), verificando-se, consequentemente, uma diminuição da percentagem dos jovens a viver sozinhos ou em coabitação. Este movimento enquadra-se no modelo de proteção continental, onde a familia é central no processo de acesso ao emprego, compensando limitações das políticas de apoio aos jovens desempregados, ao nível do emprego e habitação. É nesta perspetiva que se enquadra o caso nacional, onde a familia surge, assim, como uma compensação da falta de apoio estatal aos jovens, como podemos comprovar em Galland (1995b) e Villeneuve-Gokalp (1997). No atual contexto económico, esta questão ganha nova pertinência e representatividade, em Portugal.

Paralelamente, esta situação permite que se equacione a manutenção de uma procura regional do ensino superior ${ }^{29}$, mas também a tendência para fixação profissional a nível regional, após a obtenção do diploma de ensino superior (vejamos, a título de exemplo, os casos dos diplomados do IP Leiria - 37,6\%; IP Coimbra - 14,3\% e IP lisboa - 14,3\%, que se encontram nesta situação). Verifica-se, assim, uma correlação entre a instituição superior frequentada e a residência atual, o que pode indicar uma procura e/ou fixação, na região, após a obtenção do diploma, com já se verificara, por exemplo, em Cruz e Cruzeiro (1995) ou em Sousa (2003; 2011).

Contudo, como verificarmos em Cabrito (1997), de uma forma mais evidente, e em Balsa et al (2001); Machado et al (2003), de uma forma mais moderada, perduram evidentes desigualdades sociais no acesso ao ensino superior, materializando uma diferenciação social de origem, e confirmando uma lógica reprodutora e de seleção social. Balsa et al (idem) demonstra, mesmo, que o ensino politécnico continua a ser frequentado, principalmente, por jovens oriundos de familias desprovidas de elevados recursos económicos e socioeducativos, o que implica que o nível sociocultural e económico de origem continua a influenciar o tipo de ensino superior frequentado, não constituindo um

\footnotetext{
${ }^{29}$ Contudo assume-se que a preponderância de participantes dos Politécnicos do litoral, nesta análise poderá explicar a incidência deste fenómeno de fixação profissional nessas regiões que são tendencialmente mais desenvolvidas e consequentemente com maior oferta de oportunidades de emprego.
} 
fenómeno novo, comprovando-se o facto de, ainda hoje, se verificar uma regionalização ${ }^{30}$, na procura do ensino superior em Portugal.

Confirma-se que o "( ) assinalável esforço feito para levar ao ensino superior o maior número possível de jovens não provocou uma expansão harmónica em termos do espaço nacional, nem em função dos estratos sociais e económicos de que os alunos são originários, assim mantendo, ou reforçando, assimetrias indesejáveis (...)" (Barreto, 1996: 463).

\begin{tabular}{cc} 
Quadro 3 - Lugares de classe de origem dos participantes no Poliempreende (\%) \\
\hline EDL - Empresários, Dirigentes e Profissionais Liberais & 13,2 \\
\hline PTE - Profissionais Técnicos e de Enquadramento & 15,8 \\
\hline TI - Trabalhadores-Independentes & 3,9 \\
\hline TIPL - Trabalhadores Independentes Pluriativos & 7,9 \\
\hline Al - Agricultores Independentes & 1,3 \\
\hline EE - Empregados Executantes & 13,2 \\
\hline O - Operários & 21,1 \\
\hline AEPL - Assalariados Executantes Pluriativos & 23,7 \\
\hline Total & 100
\end{tabular}

Partimos da tipologia apresentada por Costa, Machado e Almeida (2007), que demonstra que a maioria das propostas teóricas e de investigações empíricas vinculadas na atual sociologia das classes sociais convergem para a atribuição de uma importância central aos indicadores sócio educacionais e socioprofissionais. Estes autores falam em estrutura de classes, definindo as respetivas categorias ou lugares de classe. Neste caso específico, verifica-se, no quadro 3, a maior representatividade dos Assalariados Executantes Pluriativos $(23,7 \%)$ e Operários (21,1\%), representando quase metade dos inquiridos. Este contexto social reflete-se, paralelamente, na representatividade que os trabalhadores estudantes possuem, hoje, no ensino superior politécnico.

O exercício de um trabalho, regular ou não, ao longo do curso, corresponde, em certas situações, a desejos de construção de competências individuais, mas sobretudo a necessidades financeiras. Apesar disso, representa sempre um sinal de motivação e dinamismo, reforçando a empregabilidade dos jovens, adquirindo competências e

\footnotetext{
30 Segundo Leandro (1985), é visível, durante a segunda metade da década de 80 do século XX, uma evidente procura regional de educação superior, Cruz e Cruzeiro (1995) confirmam esta tendência, na década seguinte.
} 
saberes complementares à formação académica. Para Lefresne (2003), a questão da primeira experiência de trabalho, ao longo do percurso escolar, permite uma socialização laboral e constitui um processo cognitivo de interação entre conhecimentos escolares e experiência de trabalho, bem como um processo de constituição de um recurso de acesso a informação, que lhes permite situar-se melhor perante o mercado laboral. Béduwé e Giret (2004) avançam, mesmo, com o conceito de pré-inseridos ${ }^{31}$, correspondendo aos que exercem uma profissão estável, inerente à formação frequentada.

A dificuldade reside na heterogeneidade de ocupações que geralmente os alunos vivenciam, impossibilitando traçar linearidades fenomenológicas. Este movimento de pré-inserção é particularmente pertinente no enquadramento do caso dos trabalhadores-estudantes, população cada vez mais representativa, na frequência do ensino superior, comprovando a diversificação da população estudantil, neste nível de ensino. Nesta análise, 18,4\% dos diplomados afirmam que, durante o seu percurso académico, exerciam uma atividade profissional regular a tempo inteiro. Não representando uma taxa elevada, considerando dados anteriores (Sousa, 2003; 2011), é, contudo, representativa, se tivermos em consideração que a média de idade dos inquiridos se situa, preferencialmente, abaixo dos 25 anos. Quanto à avaliação do curso/instituição frequentada, os diplomados afirmam que "O politécnico deveria apoiar mais a criação de empresas por parte dos estudantes" (média de 3,932), o que nos permite equacionar se o programa Poliempreende não deveria objetivamente constituir um programa de apoio à transição para a vida ativa e apoiar diretamente a aplicabilidade de projetos, sobretudo os vencedores que usufruem de um prémio monetário. Os restantes dois indicadores (O curso incentiva a criação de empresas - média de 2,7; O curso prepara para a criação de empresa - média 2,6) denotam que, a nível formativo, esta questão não é ainda suficientemente valorizada ${ }^{33}$. Importa, igualmente referir que

\footnotetext{
${ }^{31}$ O estar pré-inserido implica possuir profissão estável, que corresponde à formação que está realizar, - que pode constituir um movimento de potenciar as competências individuais, uma forma de financiamento dos estudos, um processo de melhoria das condições de vida, um reflexo e um sinal de motivação, uma forma de pesquisa e adaptação ao mercado e pode transparecer um contexto geográfico (dimensão de espaço urbano e a relação com a probabilidade de trabalhar) - "( ) students are involved in two types of extracurricular activities while studying at university: employment to sustain academic life, and leisure or social activities. ( ) These students' jobs may influence their future access to the labor market. (....) extra-curricular activity may influence a graduate's transition process to the labor market, for instance, by speeding up or slowing down access to employment." (Tchibozo, 2007: 37-38).

32 Escala de 1 a 5, onde o 1 corresponde a "discordo completamente" e o 5 a "concordo completamente".

${ }^{33}$ Refira-se, somente, o surgimento progressivo de unidades curriculares de empreendedorismo, em várias formações académicas, o que denota o reconhecimento da importância desta vertente na formação académica dos alunos.
} 
esta tendência é mais evidente nos diplomados que afirmam estar, atualmente, a exercer o $1^{\circ}$ emprego regular e nos que se encontram desempregados, o que poderá, igualmente, justificar estas tomadas de posição. Acrescente-se ainda, que os inquiridos revelam uma baixa participação em programas de mobilidade académica. Podemos então concluir que, apesar de facultar uma formação mais profissionalizante (Arroteia, 2002), os diplomados do ensino superior politécnico evidenciam uma posição generalizadamente negativa, no que respeita ao apoio e incentivo à criação de empresas facultado pela instituição.

Contudo, temos que referir que se verifica uma evidente heterogeneidade nas suas formações académicas e respetivas estruturas curriculares (áreas de engenharia, gestão, saúde, etc) em análise, impossibilitando que esta questão possa ser objetivamente explorada. Porém, tendo presente que a participação no programa Poliempreende pretende dinamizar a vertente empreendedora dos alunos, não deixa de se revelar curioso o facto de os diplomados não refletirem positivamente nas respostas esta situação, o que permite equacionar se identificam este programa como elemento integrante de uma política institucional de apoio à criação empresarial, no ensino superior politécnico. Esta questão encontra resposta no facto de, durante o trabalho exploratório que antecedeu esta análise, termos verificado a inexistência de projetos $^{34}$ aplicados, o que tornava mais pertinente analisar o processo de implementação do Poliempreende.

\section{5 - CONTORNOS DE IMPLEMENTAÇÃO DO POLIEMPREENDE}

Quadro 4 - Contornos de implementação do projeto dos diplomados segundo a sua Situação profissional atual

\begin{tabular}{|c|c|c|c|c|c|c|c|c|c|c|}
\hline & & & 1 & 2 & 3 & 4 & 5 & 6 & 7 & Total \\
\hline \multirow{7}{*}{$\begin{array}{c}\text { CAUSAS DE NÃO } \\
\text { APLICAÇÃO DO } \\
\text { PROJETO }\end{array}$} & $\begin{array}{c}\text { Sem problemas } \\
\text { de aplicação }\end{array}$ & $\%$ & 33,3 & 0 & 37,5 & 30,8 & 66,7 & 28,6 & 0 & 30,8 \\
\hline & $\begin{array}{l}\text { Ausência de } \\
\text { recursos } \\
\text { financeiros }\end{array}$ & $\%$ & 0 & 0 & 50 & 15,4 & 33,3 & 14,3 & 25 & 23,1 \\
\hline & $\begin{array}{l}\text { Acesso restrito } \\
\text { ao crédito }\end{array}$ & $\%$ & 0 & 0 & 0 & 23,1 & 0 & 28,6 & 0 & 12,8 \\
\hline & $\begin{array}{c}\text { Pouca } \\
\text { recetividade } \\
\text { empresarial }\end{array}$ & $\%$ & 66,7 & 100 & 0 & 0 & 0 & 0 & 25 & 10,3 \\
\hline & $\begin{array}{c}\text { Competitividade } \\
\text { do mercado }\end{array}$ & $\%$ & 0 & 0 & 12,5 & 15,4 & 0 & 0 & 0 & 7,7 \\
\hline & $\begin{array}{l}\text { Falta de apoio } \\
\text { do Politécnico }\end{array}$ & $\%$ & 0 & 0 & 0 & 7,7 & 0 & 0 & 25 & 5,1 \\
\hline & Falta de apoio & $\%$ & 0 & 0 & 0 & 0 & 0 & 14,3 & 0 & 2,6 \\
\hline
\end{tabular}

\footnotetext{
${ }^{34}$ Recorde-se que os vencedores da cada edição recebem um prémio monetário.
} 


\begin{tabular}{|c|c|c|c|c|c|c|c|c|c|c|}
\hline & $\begin{array}{c}\text { público de } \\
\text { financiamento }\end{array}$ & & & & & & & & & \\
\hline & Legislação & $\%$ & 0 & 0 & 0 & 0 & 0 & 0 & 25 & 2,6 \\
\hline & Não responde & $\%$ & 0 & 0 & 0 & 7,7 & 0 & 0 & 0 & 2,6 \\
\hline & $\begin{array}{l}\text { Já possuía } \\
\text { emprego }\end{array}$ & $\%$ & 0 & 0 & 0 & 0 & 0 & 14,3 & 0 & 2,6 \\
\hline $\begin{array}{c}\text { OBSTÁCULOS } \\
\text { DE }\end{array}$ & $\begin{array}{l}\text { Dificuldades de } \\
\text { financiamento }\end{array}$ & $\%$ & 25 & 0 & 37,5 & 23,1 & 66,7 & 71,4 & 25 & 37,5 \\
\hline \multirow[t]{7}{*}{ IMPLEMENTAÇÃO } & $\begin{array}{l}\text { Risco financeiro } \\
\text { (perder dinheiro) } \\
\end{array}$ & $\%$ & 75 & 100 & 0 & 30,8 & 0 & 28,6 & 25 & 27,5 \\
\hline & $\begin{array}{c}\text { Situação } \\
\text { económica e } \\
\text { política }\end{array}$ & $\%$ & 0 & 0 & 35 & 7,7 & 0 & 0 & 25 & 10 \\
\hline & $\begin{array}{c}\text { Falta de } \\
\text { capacidade } \\
\text { empresarial }\end{array}$ & $\%$ & 0 & 0 & 0 & 15,4 & 0 & 0 & 25 & 7,5 \\
\hline & $\begin{array}{c}\text { Falta de } \\
\text { conhecimento } \\
\text { do negócio e } \\
\text { dos clientes }\end{array}$ & $\%$ & 0 & 0 & 25 & 0 & 0 & 0 & 0 & 5 \\
\hline & Carga fiscal & $\%$ & 0 & 0 & 12,5 & 7,7 & 0 & 0 & 0 & 5 \\
\hline & $\begin{array}{c}\text { Falta da ideia } \\
\text { certa de negócio }\end{array}$ & $\%$ & 0 & 0 & 0 & 7,7 & 33,3 & 0 & 0 & 5 \\
\hline & Outra & $\%$ & 0 & 0 & 0 & 7,7 & 0 & 0 & 0 & 2,5 \\
\hline $\begin{array}{l}\text { MOTIVAÇÕES } \\
\text { DE }\end{array}$ & $\begin{array}{c}\text { Desenvolvimento } \\
\text { Profissional } \\
\end{array}$ & $\%$ & 25 & 0 & 12,5 & 30,8 & 0 & 14,3 & 50 & 22,5 \\
\hline \multirow[t]{9}{*}{ PARTICIPAÇÃO } & $\begin{array}{l}\text { Autonomia } \\
\text { profissional } \\
\end{array}$ & $\%$ & 25 & 0 & 12,5 & 23,1 & 33,3 & 14,3 & 0 & 17,5 \\
\hline & $\begin{array}{l}\text { Realizar um } \\
\text { sonho } \\
\text { profissional }\end{array}$ & $\%$ & 50 & 0 & 25 & 15,4 & 0 & 0 & 0 & 15 \\
\hline & Ganhar dinheiro & $\%$ & 0 & 0 & 12,5 & 7,7 & 0 & 0 & 50 & 10 \\
\hline & $\begin{array}{c}\text { Criar próprio } \\
\text { emprego }\end{array}$ & $\%$ & 0 & 0 & 0 & 7,7 & 33,3 & 28,6 & 0 & 10 \\
\hline & Ambição/poder & $\%$ & 0 & 100 & 12,5 & 0 & 0 & 14,3 & 0 & 7,5 \\
\hline & $\begin{array}{c}\text { Independência } \\
\text { pessoal }\end{array}$ & $\%$ & 0 & 0 & 12,5 & 7,7 & 0 & 0 & 0 & 5 \\
\hline & Criar algo & $\%$ & 0 & 0 & 0 & 7,7 & 0 & 14,3 & 0 & 5 \\
\hline & $\begin{array}{c}\text { Reconhecimento } \\
\text { Social }\end{array}$ & $\%$ & 0 & 0 & 12,5 & 0 & 0 & 14,3 & 0 & 5 \\
\hline & $\begin{array}{l}\text { Obter estatuto e } \\
\text { prestígio social }\end{array}$ & $\%$ & 0 & 0 & 0 & 0 & 33,3 & 0 & 0 & 2,5 \\
\hline \multirow{4}{*}{$\begin{array}{l}\text { IMPORTÂNCIA DA } \\
\text { PARTICIPAÇÃO } \\
\text { NO PERCURSO } \\
\text { PROFISSIONAL }\end{array}$} & Muito importante & $\%$ & 33,3 & 100 & 25 & 30,8 & 33,3 & 16,7 & 75 & 34,2 \\
\hline & Importante & $\%$ & 66,7 & 0 & 75 & 30,8 & 0 & 66,7 & 25 & 44,7 \\
\hline & Nada importante & $\%$ & 0 & 0 & 0 & 7,7 & 0 & 0 & 0 & 2,6 \\
\hline & Não responde & $\%$ & 0 & 0 & 0 & 30,8 & 66,7 & 16,7 & 0 & 18,4 \\
\hline \multirow{2}{*}{$\begin{array}{l}\text { LIGAÇÃO COM O } \\
\text { POLTÉCNICO }\end{array}$} & Sim & $\%$ & 50 & 0 & 12,5 & 23,1 & 66,7 & 57,1 & 0 & 30 \\
\hline & Não & $\%$ & 50 & 100 & 87,5 & 76,9 & 33,3 & 42,9 & 100 & 70 \\
\hline \multirow[t]{4}{*}{$\begin{array}{l}\text { TIPO DE } \\
\text { LIGAÇÃO }\end{array}$} & $\begin{array}{c}\text { Continua a } \\
\text { estudar }\end{array}$ & $\%$ & 50 & 0 & 0 & 0 & 100 & 100 & 0 & 58,3 \\
\hline & Projetos de l/D & $\%$ & 50 & 100 & 0 & 33,3 & 0 & 0 & 0 & 25 \\
\hline & Recrutamento & $\%$ & 0 & 0 & 0 & 33,3 & 0 & 0 & 0 & 8,3 \\
\hline & $\begin{array}{c}\text { Recurso a } \\
\text { prestação de } \\
\text { serviços }\end{array}$ & $\%$ & 0 & 0 & 0 & 33,3 & 0 & 0 & 0 & 8,3 \\
\hline
\end{tabular}


Legenda: 1 - Possuo um novo emprego; 2- Encontro-me desempregado e não exerci qualquer tipo de emprego regular após o desempenhado no último ano do curso; 3 - Procuro $1^{\circ}$ emprego regular; 4Mantive o emprego detido e a situação profissional (funções, categoria profissional e/ou condições de trabalho); 5- Mantive o emprego detido, mas alterei situação profissional (funções, categoria profissional e/ou condições de trabalho); 6- Encontro-me desempregado; 7 - Exerço o $1^{\circ}$ emprego regular.

Importa analisar, seguidamente, os contornos e dificuldades de implementação dos projetos, as motivações de participação e sua importância nos percursos profissionais e na manutenção da ligação com a instituição de ensino superior frequentada.

$\mathrm{Na}$ análise do quadro 4, verifica-se que, quando questionados relativamente às causas de não aplicação do projetos, 30,8\% dos diplomados afirmam não ter tido problemas na sua aplicação. Esta questão é, obviamente, curiosa, só podendo ser explicada pelo facto de considerarmos que, os diplomados não equacionaram efetivamente aplicar os seus projetos. Relativamente aos restantes, 23,1\% indicam que a razão da não aplicação do projeto foi a falta de recursos financeiros, o acesso restrito ao crédito (12,8\%) e a pouca recetividade empresarial (10,3\%).

Esta tendência é reforçada quando os diplomados são questionados sobre os obstáculos de implementação dos projetos. Assim, verifica-se que $37,5 \%$ referem-se às dificuldades de financiamento (destes, 71\% estão desempregados), 27,5\% referem-se ao risco financeiro inerente (destes, $75 \%$ afirmam possuírem novo emprego, sendo que mais de $80 \%$ se situam entre os $26-40$ anos) e $10 \%$ à situação económica e política. Podemos, desta forma, concluir que são os fatores de caracter económico ${ }^{35}$ os principais limitadores na aplicação dos projetos, situação reforçada pela análise do contexto profissional dos diplomados, o que nos permite equacionar se a situação profissional atual não terá uma relação direta e condicionadora na possibilidade de aplicação dos projetos, com os quais os diplomados concorreram ao programa Poliempreende.

Quanto às motivações de participação, 22,5\% dos diplomados referem-se ao desenvolvimento profissional (dos quais 50\% exercem o $1^{\circ}$ emprego, 39,1\% são mulheres e 40\% encontram-se entre os 41 e os 50 anos), $17,5 \%$ à autonomia profissional (dos quais 23,1\% mantiveram o emprego e a situação profissional detida ainda durante o curso e 33,3\% mantiveram emprego mas alteraram situação profissional). Relativamente às motivações de participação no programa

\footnotetext{
${ }^{35}$ Veja-se a título de exemplo os resultados do Amway Global Enterpreneurship Report, onde se verificam que os portugueses, além de uma aversão evidente ao risco, inerente ao processo do empreendedorismo, evidenciam as questões económicas como o grande obstáculo ao empreendedorismo em Portugal. Relatório disponível em:

http://wuw.amwayentrepreneurshipreport.tum.de/ .
} 
Poliempreende são, sobretudo, questões como a autonomia profissional, a realização e desenvolvimento profissional e pessoal as mais referidas, o que confirma que o intuito de participação, por parte dos diplomados, é sobretudo de índole profissional.

No que respeita à importância que atribuem à participação neste programa no seu percurso profissional, 34,5\% dos diplomados afirmam que foi muito importante (saliente-se que, destes, 75\% exercem o $1^{\circ}$ emprego), 44,7\% indicam ter sido importante (destes, 66,7\% estão desempregados e 66,7\% encontram-se à procura do $1^{\circ}$ emprego, encontrando-se numa situação de desemprego de inserção).

Podemos afirmar que a participação no Poliempreende não teve, até ao momento, uma influência evidente nas trajetórias profissionais dos diplomados, isto porque, além da não implementação dos projetos, a situação profissional precária de alguns dos diplomados e o imobilismo profissional que evidenciam as suas trajetórias profissionais, refletem que a participação neste programa não influenciou, diretamente, o movimento de transição para o trabalho dos diplomados ou, indiretamente, a situação laboral já detida pelos que desempenhavam uma atividade profissional regular e a tempo inteiro, antes de terminarem o seu curso superior. Paralelamente e no que respeita à ligação dos diplomados com o Politécnico, 30\% afirmam que mantêm esta ligação, sendo que, destes, 57,1\% estão desempregados, verificando-se que é sobretudo ao nível da continuidade das trajetórias académicas que os diplomados mantêm esta ligação.

Esta situação comprova uma continuidade no investimento na educação, que poderá ser o reflexo, sobretudo, das contingências vividas, do mercado de trabalho e da inflação dos diplomas, isto porque se verifica que a maior parte encontram-se, de momento, desempregados. Esta situação reflete o papel que o ensino superior pode representar, como um "parque de estacionamento" (Pais, 2005), até os jovens conseguirem aceder a um emprego regular e a tempo inteiro. Podemos, então, concluir que existe, apesar de tudo, uma ténue ligação dos diplomados com a instituição frequentada, mesmo por parte dos que participam em programas referenciais, no que respeita ao empreendedorismo no ensino superior, durante o seu percurso académico. Resta-nos verificar quais constituem, para os diplomados, as características que associam ao empreendedorismo. 
Quadro 5 - Características associadas ao empreendedorismo segundo a sua situação profissional atual (\% de referências)

\begin{tabular}{ccccccccc}
\hline & 1 & 2 & 3 & 4 & 5 & 6 & 7 & Total \\
\hline Líder & 50 & 11,1 & 0 & 30,8 & 20 & 37,5 & 33,3 & 27,9 \\
\hline Inovador & 25 & 22,2 & 100 & 23,1 & 40 & 12,5 & 33,3 & 25,6 \\
\hline Dinâmico/Proativo & 0 & 33,3 & 0 & 30,8 & 60 & 0 & 33,3 & 25,6 \\
\hline Ambicioso/Audaz & 25 & 33,3 & 100 & 15,4 & 0 & 37,5 & 0 & 23,3 \\
\hline Criativo & 0 & 22,2 & 0 & 23,1 & 20 & 12,5 & 33,3 & 18,6 \\
\hline Persistente & 25 & 11,1 & 100 & 15,4 & 20 & 12,5 & 0 & 16,3 \\
\hline Determinado & 0 & 11,1 & 0 & 15,4 & 20 & 37,5 & 0 & 16,3 \\
\hline Eficiente & 25 & 0 & 0 & 23,1 & 0 & 12,5 & 0 & 11,6 \\
\hline Responsável & 0 & 11,1 & 0 & 15,4 & 0 & 0 & 0 & 7 \\
\hline Corajoso & 0 & 11,1 & 0 & 0 & 0 & 25 & 0 & 7 \\
\hline Autónomo & 25 & 11,1 & 0 & 0 & 0 & 0 & 0 & 4,7 \\
\hline
\end{tabular}

Legenda: 1- Possuo um novo emprego; 2- Encontro-me desempregado e não exerci qualquer tipo de emprego regular após o desempenhado no último ano do curso; 3 - Procuro $1^{\circ}$ emprego regular; 4- Mantive o emprego detido e a situação profissional (funções, categoria profissional e/ou condições de trabalho); 5- Mantive o emprego detido, mas alterei situação profissional (funções, categoria profissional e/ou condições de trabalho); 6- Encontro-me desempregado; 7 Exerço o $1^{\circ}$ emprego regular.

As características associadas pelos diplomados ao empreendedorismo são: liderança, com 27,9\% de referência (destaque para o facto de 50\% se encontrarem entre os 41-50 anos); Inovação com 25,6\%, dinamismo/proactividade com 25,6\% e ambição/audácia com 23,3\%.

Os diplomados revelam uma representação alargada sobre as características que são associadas ao empreendedorismo, situação particularmente evidente nas faixas etárias mais elevadas, o que poderá ser uma consequência direta de uma maior experiência e consciência profissional.

Genericamente, os diplomados evidenciam uma perspetiva que denota esclarecimento sobre o empreendedorismo, contudo não se torna evidente que a participação neste programa tenha contribuído para esta situação, já que são os que se encontram inseridos no mercado de trabalho há mais tempo, os que evidenciam posturas de maior clarividência. Consequentemente, não podemos confirmar objetivamente a ligação direta entre a participação neste programa e a construção de uma perspetiva mais alargada de que representa, na atualidade, o empreendedorismo.

\section{CONCLUSÕES}

Tendo presente o contexto económico e social atual, jovens e instituições de ensino superior vivem novos desafios face ao fenómeno do (des)emprego em Portugal. Consequentemente, a importância e o papel do empreendedorismo no ensino superior, intensificam-se. Programas como o Poliempreende possuem, atualmente, particular 
pertinência, face ao atual contexto económico e social, não só para reafirmar a pertinência desta temática, mas, sobretudo, para enquadrar estas novas políticas nos desafios futuros do ensino superior politécnico em Portugal. Os desafios face ao emprego vividos, atualmente, pelos jovens diplomados do ensino superior, transformaram-se numa das maiores preocupações dos mais diversos intervenientes da sociedade. - surgimento e proliferação de programas de apoio ao empreendedorismo, no ensino superior, constituem, atualmente, uma das estratégias adotadas, como forma de promoção do empreendedorismo e emprego, durante a formação, nas universidades e politécnicos.

Este movimento materializa uma necessidade crescente e evidente de melhorar a interligação entre ensino superior e mercado de trabalho e potenciar parcerias assentes na transferência de saberes, competências e tecnologia. Só assim o ensino superior poderá responder às novas exigências colocadas pelos novos contornos de emprego e pela reestruturação inerente à aplicação do processo de Bolonha em Portugal. Neste processo, o ensino politécnico possui particular responsabilidade, por um lado, por razões históricas e de conceção (Arroteia, 2002) e, por outro lado, porque enfrenta, na $1^{a}$ década do século XXl, novos desafios, alicerçados nos atuais contornos demográficos do país e no consequente aumento da competitividade, no ensino superior, a nível nacional e internacional.

Importa salientar, novamente, que as seguintes conclusões reportam-se aos inquiridos que constituem este objeto empírico específico. A questão da contextualização sociogeográfica dos mesmos, revela-se, neste contexto, particularmente pertinente, enquadrando-se no já verificado em outras situações (Sousa 2003; 2011), que os jovens, no acesso ao ensino superior, continuam a evidenciar uma procura regional de educação e, que, após a conclusão das licenciaturas, denotam uma tendência para se fixarem profissionalmente nas suas áreas de residência. Esta situação poderá ser reflexo do contexto económico e social dos alunos, já que muitos dos diplomados inquiridos pertence a uma classe de origem com baixos recursos socioeconómicos.

A procura regional da educação superior, nomeadamente o acesso e frequência dos politécnicos, reflete, ainda hoje, persistentes dicotomias nacionais e regionais, materializadas numa evidente diferenciação institucional, dentro do sistema de ensino superior binário (Arroteia, 2002; Teixeira, 2000; Alves, 2007). Quando se analisam os contextos sociais de origem dos alunos dos politécnicos e se recorda que este subsistema procurou materializar uma efetiva democratização do ensino superior, assente na diversificação e dispersão geográfica da 
oferta formativa a nível nacional (Simão e Costa, 2000), verificamos que esse objetivo se encontra, ainda hoje, inacabado, ganhando, no atual contexto económico e social, uma nova pertinência.

No que respeita à avaliação da formação superior obtida, os inquiridos referem que o ensino politécnico não privilegia, durante os cursos, de uma forma direta e curricular, o empreendedorismo. Esta situação é evidente quando os mesmos referem a pouca formação/apoio facultado, mesmo aos mais empreendedores, na criação de empresas, isto no âmbito de um ensino tendencialmente profissionalizante. Contudo, esta questão tem que ser enquadrada tendo presente a heterogeneidade de cursos superiores representados nesta análise; a título de exemplo, verifica-se uma grande discrepância na inclusão de estágios curriculares nas respetivas estruturas curriculares, durante o funcionamento dos diversos cursos dos $1^{\circ} \mathrm{s}$ ciclos aqui representados.

A pertinência da existência de um mecanismo formal e integrante do Poliempreende, que pudesse funcionar como canal de apoio direto à aplicação dos projetos, sobretudo no caso específico dos projetos vencedores/apoiados financeiramente, recorde-se que as razões/obstáculos mais apontadas pelos diplomados para a não aplicação do projeto são de índole económica, torna-se assim evidente. Esta questão ganha novas dimensões quando se constata que as principais motivações de participação neste programa referidas, são de índole profissional, consequentemente, a não aplicação dos projetos limita significativamente este processo, quer como forma de potenciar o processo de transição para o trabalho e/ou respetivo percurso profissional já instituído.

Porém, e apesar deste contexto, os inquiridos assumem que a participação se revelou importante para o seu percurso profissional, ainda que do ponto de vista prático se verifique que esta questão não teve efetiva aplicabilidade. Atendendo a situação profissional vivida, os diplomados evidenciam trajetórias profissionais que denotam um imobilismo profissional evidente, apesar da obtenção do diploma superior (no caso dos trabalhadores-estudantes) ou dificuldades no processo de transição para o trabalho (no caso dos estudantes a tempo inteiro).

Paralelamente observa-se uma ténue ligação dos mesmos com as instituições de ensino superior frequentadas, alicerçada, sobretudo, numa continuidade das trajetórias académicas. Mais uma vez se poderá equacionar se o programa Poliempreende deveria ou não incluir formalmente um período de aplicação estruturada dos projetos, de forma a maximizar todo este processo, e potenciar, paralelamente, o (re)investimento académico dos seus (ex)alunos. 
Ao nível das representações sobre empreendedorismo, os inquiridos identificam sobretudo aspetos como liderança, inovação e proactividade. Porém, verifica-se que estas posturas são mais evidentes nos diplomados de faixas etárias mais elevadas e que possuem uma maior experiência profissional.

Tendo presente não aplicação dos projetos participantes/vencedores e a situação de imobilismo/precariedade laboral vivida por parte dos diplomados inquiridos, podemos concluir que, até ao momento, a participação no Poliempreende não constituiu, para estes, um elemento integrador do processo de transição para o trabalho ou um apoio direto à criação do próprio emprego.

Este contexto denota que a problemática da transição para o trabalho, bem como a satisfação relativamente à situação profissional vivida à data de aplicação do inquérito por questionário, por parte destes diplomados, constituem elementos fundamentais na melhor compreensão deste processo, questões que nos ocuparão em análises posteriores. 


\section{Bibliografia}

Amaral, A; Teixeira P., (2000). "The rise and fall of the private sector in Portuguese higher education", Higher Education Policy. № 13, P. 245-266.

Arroteia, J. C., (2002). O Ensino Superior Politécnico em Portugal. Aveiro: UA.

Balsa, C. et al, (2001). Perfil dos estudantes do ensino superior - Desigualdades e Diferenciação. Lisboa: Colibri/CEOS.

Barbier, J. C., (1997). Les Politiques de l'emploi en Europe. Paris: Flammarion.

Beck, Ulrich, Giddens, Anthony, LASH, Scott (1994). Reflexive Modernization. Politics, Tradition and Aesthetics in the Modern Social Order. Stanford: Stanford University.

Béduwé, C; Giret, J. F., (2004). "Le travail en cours d'études a-t-il une valeur professionnelle?". Économie et Statistique, № 378-379, P. 55-79.

Boudon, R., (1977). L'inégalité des chances. La mobilité dans les sociétés industrielles. Paris: Armand Colin.

Bourdieu, P., (1980b). "Le Capital Social: Notes provisoires". Actes de la Recherche en Sciences Sociales. № 31.

C.N.E., (1990). Pareceres e Recomendações: 88-89. Lisboa: Conselho Nacional de Educação.

Costa, A. F., Machado, F. L., Almeida, J. F., (2007). "Classes sociais e recursos educativos: uma análise transnacional". In: Costa, A. F., Machado, F. L., Ávila, P., Portugal no Contexto Europeu. Sociedade e Conhecimento. Lisboa: Celta. p. 5-20.

Cruz, M. B; Cruzeiro, M. E., (1995). O Desenvolvimento do Ensino Superior em Portugal Situação e problemas de acesso. Lisboa: ME.

Dubar, C., (2001). "La construction sociale de l'insertion professionnelle". Education et Sociétés. Vol. 7, no 1, P. 23-36.

Galland, O., (1991). Sociologie de la Jeunesse. L'entrée dans la vie. Paris: Armand Colin.

Ghiglione, R; Matalon, B., (1993). O Inquérito - Teoria e Prática. Lisboa: Celta.

Giret, J. F., (2000). Pour une économie de l'insertion professionnelle des jeunes. Paris: CNRS Éditions.

lannelli C; Soro-Bonmatí, A., (2006). "Transition Pathways in Italy and Spain: Different Patterns, Similar Vulnerability?". In: Müller; Gangl, (ed.). (2006). Transitions from Education to Work in Europe - The Integration of Youth into EU Labour Markets. Oxford: Oxford University Press, P. 212-250.

Lahire, Bernard, (2005). "Patrimónios Individuais de Disposições - Para uma sociologia à escala individual". Sociologia, Problemas e Práticas. No 49, P. 11-42.

Lefresne; Florence, (2003). Les jeunes et l'emploi. Paris: La Découverte.

Machado, Fernando et al, (2003). "Classes sociais e estudantes universitários: origens, oportunidades, e orientações", Revista Crítica de Ciências Sociais. № 66, P. 45-80.

Martínez, D; Mora, J; Vila, L., (2007). "Entrepreneurs, the Self-employed and Employees amongst Young European Higher Education Graduates", European Journal of Education. Vol. 42, No. 1, P. 99-117.

McDaniel, S. A., (2006). "Self-Employment: How Individual Choices Interact with Market Economies". International Sociology. № 21, P. 796-805.

Mozzicafreddo, J., (1992). "O estado-providência em Portugal: estratégias contraditórias". Sociologia, Problemas e Práticas, №12, P. 57-89.

Müller; Gangl, (ed.), (2006). Transitions from Education to Work in Europe - The Integration of Youth into EU Labour Markets. Oxford: Oxford University Press.

OCDE, (2007). Education at a Glance - OCDE Indicators. Paris: OECD Publications.

Oliveira, Luísa, (2008). Sociologia da Inovação - A Construção Social das Técnicas e dos Mercados, Lisboa, Celta Editora.

Pais, J. M., (2005). Ganchos, tachos e biscates. Lisboa: Ambar.

Parreira; Pereira; Vieira e Brito, (2011). Empreendedorismo e Motivações Empresariais no Ensino Superior. Lisboa: Sllabo. 
Purcell, K; Wilton, N; Elias, P., (2007). "Hard Lessons for Lifelong Learners? Age and Experience in the Graduate Labour Market". Higher Education Quarterly. Vol. 61, No 1, P. 57-82.

Rose, J., (1998). Les jeunes face à l'emploi. Paris: Desclée de Brouwer.

Simão, José Veiga; Costa, António de Almeida, (2000). O Ensino Politécnico em Portugal. Braga: Conselho Coordenador dos Institutos Superiores Politécnicos.

Sousa, Luís, (2003). Processos de Transição ao trabalho: o caso dos alunos de comunicação social da ESEV. Dissertação de Mestrado. Lisboa: ISCTE.

Sousa, Luís (2011). Diplomas e (Des)Emprego: um estudo de caso. Dissertação de Doutoramento. Porto: FLUP.

Tchibozo, G., (2007). "Extra-Curricular Activity and the Transition from Higher Education to Work: A Survey of Graduates in the United Kingdom", Higher Education Quarterly, Volume $61, N^{\circ} 1$, P. 37-56.

Teichler, Ulrich, (2005). Graduados y empleo: investigation, metodologia y resultados - Los casos de Europa, Japón, Argentina e Uruguay. Buenos Aires. Niño y Dávida Editores.

Walther et al, (Eds), (2002). Misleading Trajectories - Integration Policies for Young Adults in Europe?. Opladen: Leske Budrich.

Villeneuve-Gokalp, C., (1997). "Le départ de chez les parents: définitions d'un processus complexe". Économie et Statistique. № 304-305, P. 149-162.

Villeneuve-Gokalp, C., (2000). "Les jeunes partent toujours au même âge de chez leurs parents". Économie et Statistique. No 337-338, P. 61-80. 